\title{
Novel silicone-ionic liquid composite with keratin utilized as pressure sensor
}

\author{
Liu, Xue; Nie, Yi; Yu, Liyun; Zhang, Suojiang; Skov, Anne Ladegaard
}

Published in:

Electroactive Polymer Actuators and Devices (EAPAD) XXII

Link to article, DOI:

$10.1117 / 12.2558412$

Publication date:

2020

Document Version

Publisher's PDF, also known as Version of record

Link back to DTU Orbit

Citation (APA):

Liu, X., Nie, Y., Yu, L., Zhang, S., \& Skov, A. L. (2020). Novel silicone-ionic liquid composite with keratin utilized as pressure sensor. In Y. Bar-Cohen, I. A. Anderson, \& H. R. Shea (Eds.), Electroactive Polymer Actuators and Devices (EAPAD) XXII [113750R] SPIE - International Society for Optical Engineering. Proceedings of SPIE The International Society for Optical Engineering Vol. 11375 https://doi.org/10.1117/12.2558412

\section{General rights}

Copyright and moral rights for the publications made accessible in the public portal are retained by the authors and/or other copyright owners and it is a condition of accessing publications that users recognise and abide by the legal requirements associated with these rights.

- Users may download and print one copy of any publication from the public portal for the purpose of private study or research.

- You may not further distribute the material or use it for any profit-making activity or commercial gain

- You may freely distribute the URL identifying the publication in the public portal 


\section{Novel silicone-ionic liquid composite with keratin utilized as pressure sensor}

Liu, Xue, Nie, Yi, Yu, Liyun, Zhang, Suojiang, Skov, Anne Ladegaard

Xue Liu, Yi Nie, Liyun Yu, Suojiang Zhang, Anne Ladegaard Skov, "Novel silicone-ionic liquid composite with keratin utilized as pressure sensor," Proc. SPIE 11375, Electroactive Polymer Actuators and Devices (EAPAD) XXII, 113750R (22 April 2020); doi: 10.1117/12.2558412

Event: SPIE Smart Structures + Nondestructive Evaluation, 2020, Online Only, California, United States 


\title{
Novel silicone-ionic liquid composite with keratin utilized as pressure sensor
}

\author{
Xue Liu ${ }^{\mathrm{ab}}$, Yi Nie ${ }^{\mathrm{b}}$, Liyun Yu${ }^{\mathrm{a}}$, Suojiang Zhang ${ }^{\mathrm{b}}$, Anne Ladegaard Skov*a \\ ${ }^{a}$ Danish Polymer Center, Department of Chemical and Biochemical Engineering, Technical \\ University of Denmark, Kgs. Lyngby, Denmark; ${ }^{\mathrm{b}}$ Beijing Key Laboratory of Ionic Liquids Clean \\ Process, Institute of Process Engineering, Chinese Academy of Sciences, Beijing, China
}

\begin{abstract}
Dielectric elastomer (DE) sensors have great potential for applications in soft robotics, wearable devices and medical diagnostic. A novel pressure sensor with remarkably improved force sensing characteristics was obtained through combined usage of polydimethylsiloxane (PDMS) and ionic liquid (IL). The regenerated keratin from wool was added and dispersed homogeneously in the PDMS matrix acting as reinforcing fillers. The influence of the amount of IL on the electro-mechanical properties of the composites was investigated. One obvious result was that the permittivity of the ILcontaining elastomers increased dramatically with the increased amount of IL loaded. Furthermore, the sensitivity of the composite elastomers as pressure sensors was investigated by recording the response of the voltage when a small force is applied to the top surface of the pressure sensor. The elastomers with IL loaded exhibit excellent response of the voltage and the maximum sensitivity of the composite elastomer is $2.64 \mathrm{mV} / \mathrm{N}$.
\end{abstract}

Keywords: Polydimethylsiloxane, ionic liquid, keratin, pressure sensor, high sensitivity

\section{INTRODUCTION}

Pressure sensors have attracted much attention over the past few years due to their various applications in electronic skin $^{[1-3]}$, soft robotics ${ }^{[4-5]}$ and energy harvesting ${ }^{[6-8]}$. Various types of sensing technologies have been explored based on force-induced changes in piezoresistivity, capacitance and piezoelectricity ${ }^{[9-10]}$. In recent years, enormous efforts have been made towards improving the performance of pressure sensors. A lot of nanomaterials, including carbon nanotubes ${ }^{[11-14]}$, gold/silver nanowires ${ }^{[15-18]}$, graphene nanosheets ${ }^{[19-21]}$, metal nanoparticles ${ }^{[22-23]}$, have been chosen for incorporation with polymers to fabricate novel, more sensitive pressure sensors. Tao et al. ${ }^{[19]}$ proposed a graphene-paper pressure sensor that shows excellent performance in the range of $0-20 \mathrm{kPa}$, and a sensitivity up to $17.2 \mathrm{kPa}^{-1}$ with a response time of $120 \mathrm{~ms}$. Cho et al. ${ }^{[24]}$ presented a flexible capacitive pressure sensor that shows superior pressure sensing performance with a broad sensing range and fast response time. A flexible, highly sensitive pressure sensor based on an ionic liquid gel film was reported by Zhang et al. ${ }^{[25]}$ The reported pressure sensor has a high sensitivity of $15.4 \mathrm{kPa}^{-1}$ and a wide detection range sensing from $5 \mathrm{~Pa}$ to $5 \mathrm{kPa}$. However, a problem reveals from the above pressure sensors that a pressure sensor fabricated by incorporating polymers with nanomaterials has high sensitivity, but also exhibits limited stretchability, complex preparation process and high cost, which limit its application to a large extent. Therefore, it is necessary to develop a flexible sensor with high sensitivity and facile fabrication process as smart sensors for further application.

Ionic liquids (ILs), which have high permittivity and chemical stability, are a class of functional materials for novel pressure sensors for improvement of their performance ${ }^{[26]}$. However, the poor electromechanical stability of ILs limits their further application as pressure sensors. Therefore, an ionic pressure sensor based on polymer composites with ILs, possessing both the elasticity of the polymer and the electrical conduction of the ILs, has received a lot of attention from researchers ${ }^{[25,27-28]}$. For example, a highly sensitive ionic pressure sensor with a microstructured dielectric layer with a sensitivity of $35.96 \mathrm{kPa}^{-1}$ has been prepared by Su et al. ${ }^{[29]}$. Despite the great progress in ionic pressure sensors achieved so far, the development of ionic pressure sensor are stilled limited due to complicated fabrication processes and high cost.

Silicone elastomers represent an excellent matrix for sensors ${ }^{[30-31]}$ due to their inherent stability ${ }^{[32-33]}$, also upon elevated temperatures ${ }^{[34]}$. However, silicone polymers are usually difficult to mix with other components and therefore tedious mixing schemes are usually required to ensure homogeneous composites. 
Herein, a novel silicone-based composite consisting of silicone elastomer with ionic liquid and keratin was developed. Moreover, keratin, which has excellent biocompatibility and stability, was for the first time used in silicone elastomers as a reinforcing filler. This method not only improves the performance of the material as pressure sensors but it is also simple and facile, and thereby demonstrates a great potential for large-scale production of ionic materials. The effect of the amount of IL on the electro-mechanical properties of the composites was investigated. The presence of IL not only increased the dielectric permittivity of the resulting elastomer, but also benefitted to an increased pressure sensitivity. Especially, a maximum sensitivity of the composite elastomer up to $2.64 \mathrm{mV} / \mathrm{N}$ was demonstrated. Therefore, this novel pressure sensor will have great potential in the fields of smart skins, healthcare, and wearable devices, amongst others.

\section{EXPERIMENTAL}

\subsection{Materials}

Vinyl-terminated PDMS, DMS-V31 $\left(\mathrm{Mn}=28000 \mathrm{~g} \mathrm{~mol}^{-1}\right)$ and a cross-linker HMS-301 $\left(\mathrm{Mn}=1950 \mathrm{~g} \mathrm{~mol}^{-1}\right)$ were obtained from Gelest Inc, USA. The regenerated keratin from wool was purchased from Tokyo Chemical Industry Co., Ltd, and the platinum cyclovinylmethyl siloxane complex catalyst (511) was purchased from Hanse Chemie, Germany. 1-butyl-3-methylimidazolium hexafluoroantimonate $\left(\mathrm{BmimSbF}_{6}\right)$ was purchased from Chengjie Chemicals Ltd, China. The structures of the chemicals can be seen in Figure 1.

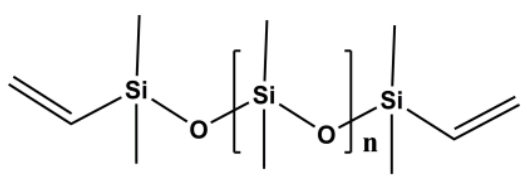

V31

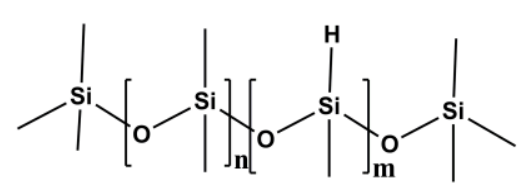

HMS301

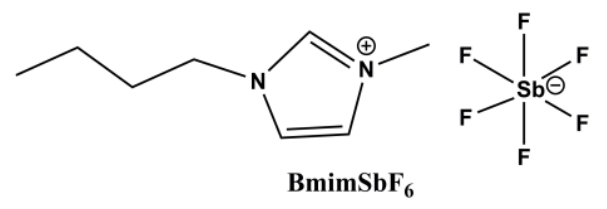

Figure 1 Structures of telechelic vinyl functionalized PDMS (V31), hydride functional crosslinker (HMS301), and ionic liquid $\mathrm{BmimSbF}_{6}$ used in this work.

\subsection{Fabrication of $\mathrm{BmimSbF}_{6}$ loaded pressure sensor}

The fabrication of the $\mathrm{BmimSbF}_{6}$ loaded pressure sensor is simple and facile, as mentioned previously. First, vinylterminated PDMS, DMS-V31 (5g, $0.18 \mathrm{mmol})$, cross-linker HMS-301 (0.1045g, $0.0536 \mathrm{mmol})$ and the catalyst (Pt 511) (15 ppm) were mixed using a speed mixer (DAC 150.1 FVZ-K, Synergy Devices Ltd, UK) at 3500 revolutions per minute (rpm) for 2 min. on a FlackTek Inc. The proportion of chemicals was based on previous research ${ }^{[35]}$. Thereafter, keratin $(25 \mathrm{wt} \%)$ and $\mathrm{BmimSbF}_{6}$ were added in the mixture as solid filler and liquid filler, respectively, and the mixture was speedmixed once more. The homogenous mixture was coated on a glass substrate using a film applicator (3540 bird, Elcometer, Germany). Then, the film was cured in the oven at $80^{\circ} \mathrm{C}$ for $2 \mathrm{~h}$, after which, individual sensors were cut from the film with $5 \mathrm{~mm} * 5 \mathrm{~mm}$. The copper sheets were attached to the film as electrodes.

\subsection{Fourier transform infrared spectroscopy (FT-IR) determination}

Fourier transform infrared spectroscopy (FT-IR) spectra of the samples were conducted using a Nicolet iS50 FT-IR fitted with a diamond crystal attenuated total reflection accessory (ATR), which operated in the range of $4000-400 \mathrm{~cm}^{-1}$ at a resolution of $4 \mathrm{~cm}^{-1}$ and 32 scans per measurement. All the spectra were baseline-corrected.

\subsection{Dielectric properties determination}

Dielectric relaxation spectroscopy (DRS) was carried out using a Novocontrol Alpha-A high-performance frequency analyser (Novocontrol Technologies $\mathrm{GmbH} \& \mathrm{Co}$, Germany). The dielectric properties were tested in the frequency 
range $10^{-1}$ to $10^{6} \mathrm{~Hz}$ at room temperature and with a low electrical field (about $1 \mathrm{~V} \mathrm{~mm}^{-1}$ ). The thickness of the tested samples was $1 \mathrm{~mm}$, and the diameter was $20 \mathrm{~mm}$.

\subsection{Scanning electron microscopy (SEM) observation}

The morphology of the samples was investigated with an FEI Quanta 200 ESEM (Thermo Fisher Scientific, USA) scanning electron microscope. This system was equipped with a field emission gun. The samples were coated with an approximately $5 \mathrm{~nm}$ thick gold layer by means of a sputter coater (Q150R ES, Quorum Technologies, UK) under vacuum condition and a current of $40 \mathrm{~mA}$ for 10 seconds before test. The sample's cross-section was detected with a secondary electron detector (SE) for an incident electron beam of spot 3.5 accelerated to $10 \mathrm{k} \mathrm{eV}$.

\subsection{Voltage response test platform}

A voltage response test platform was designed and set up to study the sensing performance of the fabricated $\mathrm{BmimSbF}_{6}$ loaded pressure sensor. This platform consists of a personal computer (PC)-controlled wave-maker and a signal acquisition system. A control signal was generated via National Instruments' LabVIEW software, and then the signal was recorded by an Asahi Seisakusyo APD-050FCA controller. A small force stimulus was generated by the wavemaker (SL-0505, Asahi Seisakusyo) and applied to the top surface of the pressure sensor via a shaker rod. The force that was applied to the pressure sensor was measured by a load cell (ZNLBM-1KG Micro Load cell, Bengbu Zongnuo Sensor Inc.). The voltage data generated by the pressure sensor was recorded using a National Instruments PCIe-6351 data acquisition board. The sensitivity (S) was calculated based on the following equation:

$$
\mathrm{S}=\frac{\mathrm{d}(\Delta \mathrm{V})}{\mathrm{dF}}
$$

where $\Delta \mathrm{V}$ is the relative voltage change, $\mathrm{F}$ is the applied force ${ }^{[27]}$.

\section{RESULTS AND DISCUSSION}

\subsection{Morphology of ionic liquid in elastomer films}

In order to verify that the $\mathrm{BmiSbF}_{6}$ is loaded successfully into the silicone elastomer, the FT-IR spectra are investigated. As illustrated in Figure 2, all films loaded with $\mathrm{BmimSbF}_{6}$ show distinctive $\mathrm{C}-\mathrm{H}$ and $\mathrm{N}-\mathrm{H}$ stretching peaks at approximately $3200 \mathrm{~cm}^{-1}$ and $3180 \mathrm{~cm}^{-1}$, respectively, and all of the films display the characteristic peaks of the imidazole ring at $1580 \mathrm{~cm}^{-1}$. The imidazole peaks of the material with $70 \mathrm{phr} \mathrm{BmimSbF}_{6}$ are sharper than those of the materials with low amount of $\mathrm{BmimSbF}_{6}$, thereby confirming the higher amount of $\mathrm{BmimSbF}_{6}$ presents in this material.

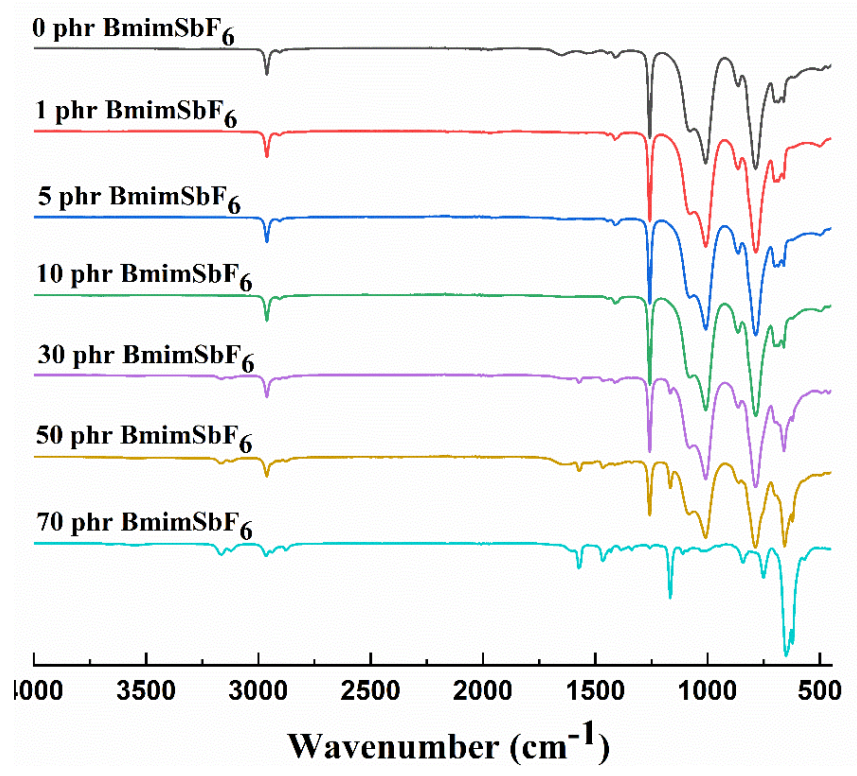

Figure 2 FT-IR spectra of films with different amounts of BmimSbF 6 loaded. 
The morphology of the samples was investigated by using scanning electron microscope (SEM). As shown in Figure 3, regenerated keratin powders (white dots) are evenly dispersed on the surface of the elastomer films. It can be clearly observed that $\mathrm{BmimSbF}_{6}$ droplets (black dots) are present in the films with $\mathrm{BmimSbF}_{6}$ loadings, and the higher loadings of the $\mathrm{BmimSbF}_{6}$, the more $\mathrm{BmimSbF}_{6}$ droplets, as would also be expected. Furthermore, the SEM images show that the $\mathrm{BmimSbF}_{6}$ is well dispersed in the silicone network.
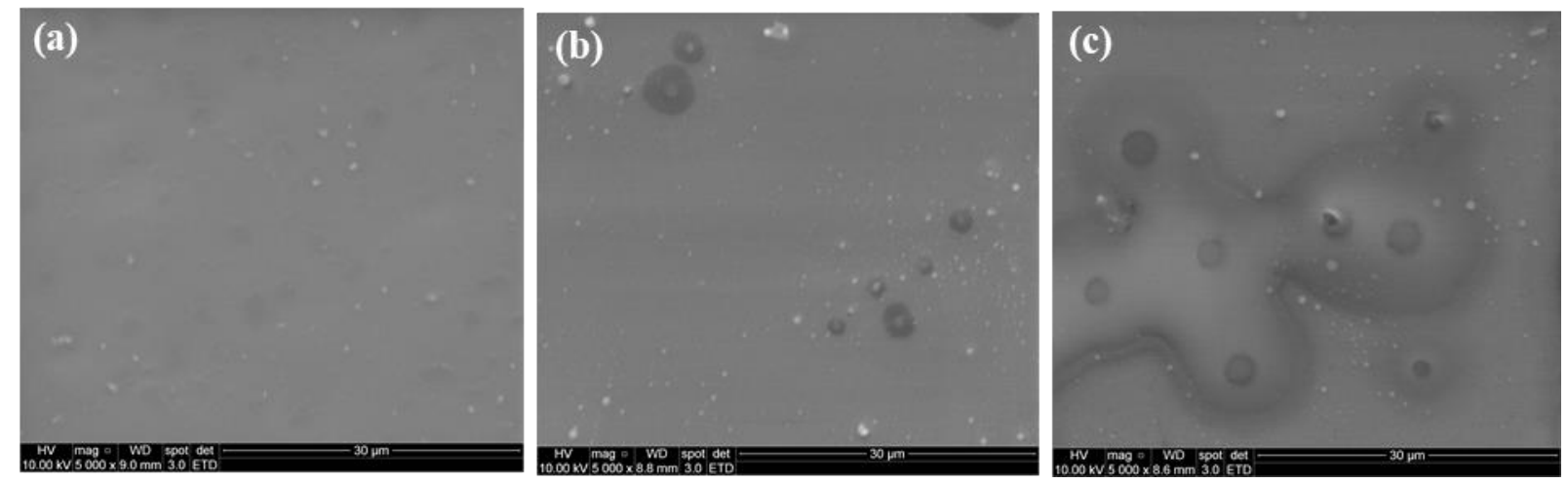

Figure 3 SEM images of elastomers, (a) pure PDMS, (b) PDMS with 10 phr BmimSbF 6 loaded, and (c) PDMS with 70 phr $\mathrm{BmimSbF}_{6}$ loaded.

\subsection{Effect of the BmimSbF 6 amount on the dielectric properties}

The dielectric properties of the films with different $\mathrm{BmimSbF}_{6}$ loadings were investigated as a function of frequency. Unlike conventional PDMS elastomers, these films with $\mathrm{BmimSbF}_{6}$ exhibit high permittivity, as shown in Figure 4 . The dielectric permittivity of elastomers with $\mathrm{BmimSbF}_{6}$ increased in line with the increased amount of $\mathrm{BmimSbF}_{6}$, while the dielectric permittivity of the elastomer with $70 \mathrm{phr} \mathrm{BmimSbF}_{6}$ has the highest permittivity. The dielectric permittivity at $10^{6} \mathrm{~Hz}$ increased from 2.24 for the pure film up to 10.3 for the sample with $70 \mathrm{phr} \mathrm{BmimSbF}_{6}$. In other words, the dielectric permittivity of an elastomer with $70 \mathrm{phr} \mathrm{BmimSbF}_{6}$ has a $4.6 \mathrm{x}$ increase compared to the pure PDMS elastomer. The storage permittivity at $10^{6} \mathrm{~Hz}$ and $10^{-1} \mathrm{~Hz}$ are also presented in Table 1.

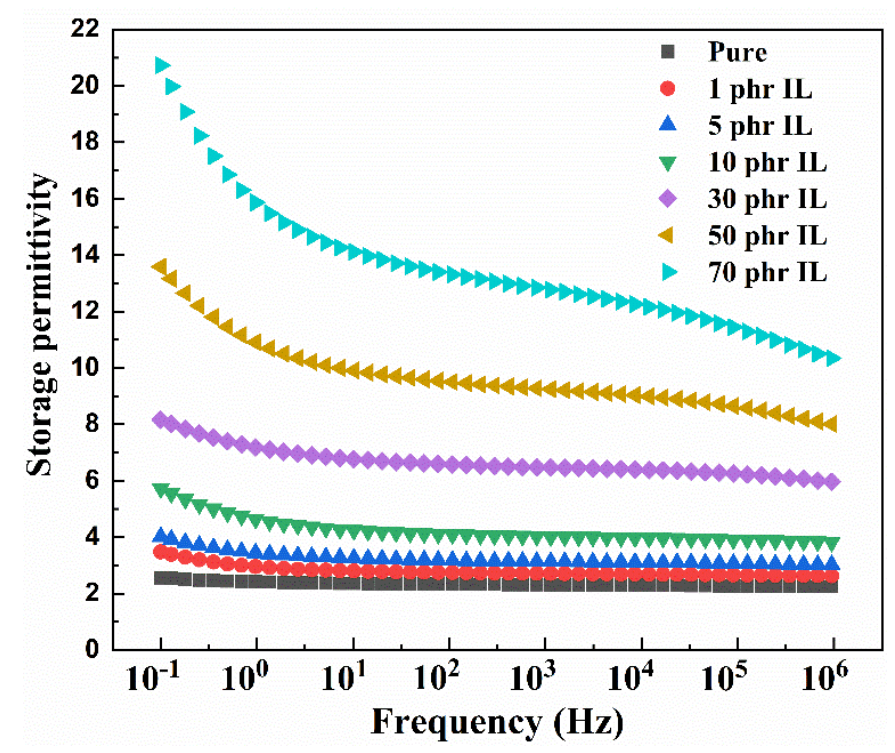

Figure 4 Storage permittivity of films with different amounts of BmimSbF6 at room temperature. 
Table 1 Dielectric properties of the investigated elastomer composites at room temperature.

\begin{tabular}{cccccccc}
\hline Samples & Pure & $\begin{array}{c}1 \mathrm{phr} \\
\mathrm{BmimSbF}_{6}\end{array}$ & $\begin{array}{c}5 \mathrm{phr} \\
\mathrm{BmimSbF}_{6}\end{array}$ & $\begin{array}{c}10 \mathrm{phr} \\
\mathrm{BmimSbF}_{6}\end{array}$ & $\begin{array}{c}30 \mathrm{phr} \\
\mathrm{BmimSbF}_{6}\end{array}$ & $\begin{array}{c}50 \mathrm{phr} \\
\mathrm{BmimSbF}_{6}\end{array}$ & $\begin{array}{c}70 \mathrm{phr} \\
\mathrm{BmimSbF}_{6}\end{array}$ \\
\hline $\begin{array}{c}\text { Permittivity } \\
\text { at } 10^{6} \mathrm{~Hz}\end{array}$ & 2.24 & 2.87 & 3.15 & 3.90 & 6.05 & 8.10 & 10.34 \\
$\begin{array}{c}\text { Permittivity } \\
\text { at } 10^{-1} \mathrm{~Hz}\end{array}$ & 2.56 & 3.57 & 4.00 & 5.61 & 8.24 & 13.70 & 20.73 \\
\hline
\end{tabular}

\subsection{Effect of the BmimSbF 6 amount on the response of the voltage}

To evaluate the performance of the pressure sensors, a dedicated test bench consisting of a personal computer (PC)controlled wave-maker and a signal acquisition system was designed. To describe the effect of the amount of $\mathrm{BmimSbF}_{6}$ on the performance of the films as pressure sensors, the voltage change curves upon a constant force $1.1 \mathrm{~N}$ for the different elastomers are compared in Figure 5. The developed sensors showed tunable voltage change depending on the loading of $\mathrm{BmimSbF}_{6}$. The voltage change of the films increased with increasing loadings of the $\mathrm{BmimSbF}_{6}$. The pure PDMS does not respond to force changes (Fig. 5b), and the film with $70 \mathrm{phr} \mathrm{BmimSbF}_{6}$ exhibited the highest voltage change (Fig. 5d). This behavior indicated that the addition of $\mathrm{BmimSbF}_{6}$ has a positive effect on the response of elastomer film to force.
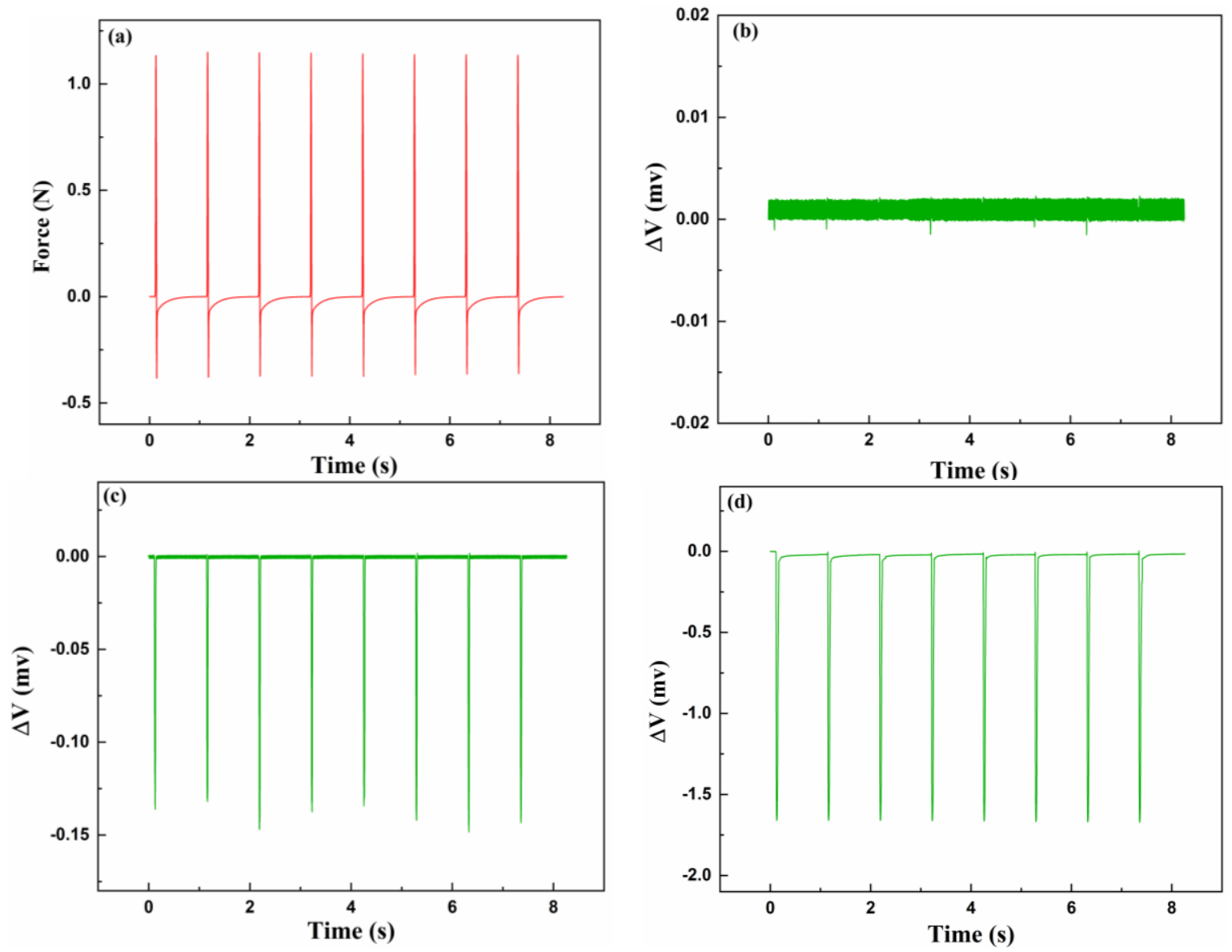

Figure 5 Voltage changes of films with different amounts of BmimSbF6 upon a constant force 1.1 N, (a) Applied force, (b) Voltage changes of film without $\mathrm{BmimSbF}_{6}$, (c) Voltage changes of film with $50 \mathrm{phr} \mathrm{BmimSbF}_{6}$, and (d) Voltage changes of film with $70 \mathrm{phr} \mathrm{BmimSbF}_{6}$. 


\subsection{Sensitivity of the film with $\mathrm{BmimSbF}_{6}$ loaded}

The sensitivity of the pressure sensor with $70 \mathrm{phr} \mathrm{BmimSbF}_{6}$ loaded was calculated based on equation (1). As shown in Figure 6, the pressure sensor with $70 \mathrm{phr} \mathrm{BmiSbF}_{6}$ has an obvious voltage change when a small force is applied. It also can be seen that the sensitivity of the pressure sensor with the thickness of $800 \mu \mathrm{m}$ is $1.88 \mathrm{mV} / \mathrm{N}$. Based on previous report, the thickness of the elastomer film has effect on the sensitivity of the pressure sensor ${ }^{[36]}$. Therefore, the effect of the thickness of the pressure sensor on the sensitivity was also investigated by calculating the sensitivity of the materials with different thicknesses. In Figure 6, the sensitivity of the pressure sensor with a thickness of $160 \mu \mathrm{m}$ is $2.64 \mathrm{mV} / \mathrm{N}$, which is much higher than that of the pressure sensor with a thickness of $800 \mu \mathrm{m}$. This result indicated, as expected, that the thickness of the pressure sensor plays an important role on the sensitivity of the pressure sensor, which is consistent with the conclusions drawn from the literature ${ }^{[36]}$.

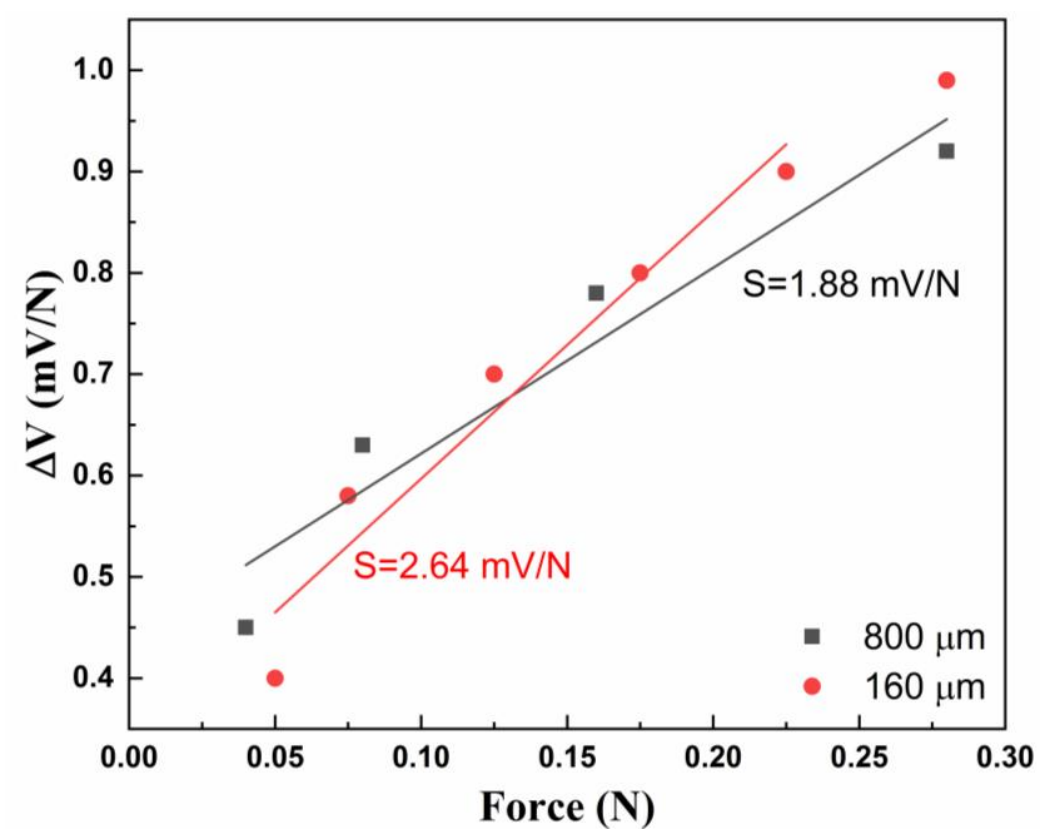

Figure 6 Sensitivity of film with 70 phr BmimSbF 6 upon varying forces and thicknesses.

\section{CONCLUSION}

In summary, a novel high-performance of pressure sensor was fabricated by incorporating the ionic liquid $\mathrm{BmimSbF}_{6}$ into a silicone elastomer, and the regenerated keratin from wool was added as solid fillers to strengthen the elastomer. The effect of the loading of $\mathrm{BmimSbF}_{6}$ on the performance of the elastomer composites as pressure sensors was also investigated. Dielectric permittivity increased in line with increased amount of $\mathrm{BmimSbF}_{6}$, while the dielectric permittivity of the film with $70 \mathrm{phr} \mathrm{BmimSbF}_{6}$ was 4.6x higher than that of the pristine silicone elastomer. The developed sensor showed tunable voltage change, depending on the loaded amount of $\mathrm{BmimSbF}_{6}$, and the optimized pressure sensor exhibited excellent force sensing characteristics. Especially, the sensitivity of the pressure sensor with $70 \mathrm{phr} \mathrm{BmimSbF}_{6}$ is $2.64 \mathrm{mV} / \mathrm{N}$. Moreover, the thickness of the pressure sensor also effects the sensitivity, and thinner film showing higher sensitivity for the pressure sensor. The excellent performance and facile process suggested the potential application of the novel pressure sensor in the healthcare and smart wearable devices.

\section{ACKNOWLEDGEMENTS}

This work was supported by the Department of Chemical and Biochemical Engineering, Technical University of Denmark, and the National Natural Science Foundation of China. 


\section{CONFLICT OF INTEREST}

The authors declare no conflict of interest.

\section{REFERENCES}

[1] Gong, S.; Schwalb, W.; Wang, Y.; Chen, Y.; Tang, Y.; Si, J.; Shirinzadeh, B.; Cheng, W., "A wearable and highly sensitive pressure sensor with ultrathin gold nanowires," Nat Commun 5, 3132 (2014).

[2] Liao, X.; Zhang, Z.; Kang, Z.; Gao, F.; Liao, Q.; Zhang, Y., "Ultrasensitive and stretchable resistive strain sensors designed for wearable electronics," Mater. Horiz. 4 (3), 502-510 (2017).

[3] Son, D.; Kang, J.; Vardoulis, O.; Kim, Y.; Matsuhisa, N.; Oh, J. Y.; To, J. W.; Mun, J.; Katsumata, T.; Liu, Y.; McGuire, A. F.; Krason, M.; Molina-Lopez, F.; Ham, J.; Kraft, U.; Lee, Y.; Yun, Y.; Tok, J. B.; Bao, Z., "An integrated self-healable electronic skin system fabricated via dynamic reconstruction of a nanostructured conducting network," Nat. Nanotechnol. 13 (11), 1057-1065 (2018).

[4] Emon, M. O. F.; Alkadi, F.; Philip, D. G.; Kim, D.-H.; Lee, K.-C.; Choi, J.-W., "Multi-material 3D printing of a soft pressure sensor," Addit. Manuf. 28, 629-638 (2019).

[5] Zhou, J.; Xu, X.; Xin, Y.; Lubineau, G., "Coaxial thermoplastic elastomer-wrapped carbon nanotube fibers for deformable and wearable strain sensors," Adv. Funct. Mater. 28 (16), 1705591 (2018).

[6] Wang, Z. L.; Wu, W., "Nanotechnology - enabled energy harvesting for self - powered micro - /nanosystems," Angew. Chem. Int. Edit. 51 (47), 11700-11721 (2012).

[7] Yang, Y.; Zhang, H.; Lin, Z.-H.; Zhou, Y. S.; Jing, Q.; Su, Y.; Yang, J.; Chen, J.; Hu, C.; Wang, Z. L., "Human skin based triboelectric nanogenerators for harvesting biomechanical energy and as self-powered active tactile sensor system," ACS Nano. 7 (10), 9213-9222 (2013).

[8] Hu, Y.; Yang, J.; Jing, Q.; Niu, S.; Wu, W.; Wang, Z. L., "Triboelectric nanogenerator built on suspended 3D spiral structure as vibration and positioning sensor and wave energy harvester," ACS Nano. 7 (11), 1042410432 (2013).

[9] Heikenfeld, J.; Jajack, A.; Rogers, J.; Gutruf, P.; Tian, L.; Pan, T.; Li, R.; Khine, M.; Kim, J.; Wang, J.; Kim, J., "Wearable sensors: modalities, challenges, and prospects," Lab Chip 18 (2), 217-248 (2018).

[10] Zang, Y.; Zhang, F.; Di, C.-a.; Zhu, D., "Advances of flexible pressure sensors toward artificial intelligence and health care applications," Mater. Horiz. 2 (2), 140-156 (2015).

[11]Qin, Z.; Sun, X.; Yu, Q.; Zhang, H.; Wu, X.; Yao, M.; Liu, W.; Yao, F.; Li, J., "Carbon nanotubes/ hydrophobically associated hydrogels as ultrastretchable, highly sensitive, stable strain, and sressure sensors," ACS Appl. Mater. Interfaces 12 (4), 4944-4953 (2020).

[12] Zhang, Z.; Zhang, Y.; Jiang, X.; Bukhari, H.; Zhang, Z.; Han, W.; Xie, E., "Simple and efficient pressure sensor based on PDMS wrapped CNT arrays," Carbon 155, 71-76 (2019).

[13] Nie, B.; Li, X.; Shao, J.; Li, X.; Tian, H.; Wang, D.; Zhang, Q.; Lu, B., "Flexible and transparent strain sensors with embedded multiwalled carbon nanotubes meshes," ACS Appl. Mater. Interfaces 9 (46), 40681-40689 (2017).

[14] Chen, H.; Su, Z.; Song, Y.; Cheng, X.; Chen, X.; Meng, B.; Song, Z.; Chen, D.; Zhang, H., "Omnidirectional bending and pressure sensor based on stretchable CNT-PU sponge," Adv. Funct. Mater. 27 (3), 1604434 (2017).

[15] Lee, S.; Reuveny, A.; Reeder, J.; Lee, S.; Jin, H.; Liu, Q.; Yokota, T.; Sekitani, T.; Isoyama, T.; Abe, Y.; Suo, Z.; Someya, T., "A transparent bending-insensitive pressure sensor," Nat. Nanotechnol. 11 (5), 472-8 (2016).

[16] Topcu, G.; Demir, M. M., "Effect of chain topology on plasmonic properties of pressure sensor films based on poly(acrylamide) and Au nanoparticles," Sensor Actuat. A : Phys. 295, 237-243 (2019).

[17] Joo, Y.; Byun, J.; Seong, N.; Ha, J.; Kim, H.; Kim, S.; Kim, T.; Im, H.; Kim, D.; Hong, Y., "Silver nanowireembedded PDMS with a multiscale structure for a highly sensitive and robust flexible pressure sensor," Nanoscale 7 (14), 6208-15 (2015).

[18] Jeong, H.; Noh, Y.; Ko, S. H.; Lee, D., "Flexible resistive pressure sensor with silver nanowire networks embedded in polymer using natural formation of air gap," Compos. Sci. Technol. 174, 50-57 (2019).

[19] Tao, L. Q.; Zhang, K. N.; Tian, H.; Liu, Y.; Wang, D. Y.; Chen, Y. Q.; Yang, Y.; Ren, T. L., "Graphene-paper pressure sensor for detecting human motions," ACS Nano. 11 (9), 8790-8795 (2017). 
[20]He, J.; Xiao, P.; Lu, W.; Shi, J.; Zhang, L.; Liang, Y.; Pan, C.; Kuo, S.-W.; Chen, T., "A Universal high accuracy wearable pulse monitoring system via high sensitivity and large linearity graphene pressure sensor," Nano. Energy 59, 422-433 (2019).

[21] Chun, S.; Kim, D. W.; Kim, J.; Pang, C., "A transparent, glue-free, skin-attachable graphene pressure sensor with micropillars for skin-elasticity measurement," Nanotechnology 30 (33), 335501 (2019).

[22] Segev-Bar, M.; Landman, A.; Nir-Shapira, M.; Shuster, G.; Haick, H., "Tunable touch sensor and combined sensing platform: toward nanoparticle-based electronic skin," ACS Appl. Mater. Interfaces 5 (12), 5531-41 (2013).

[23] Sangeetha, N. M.; Decorde, N.; Viallet, B.; Viau, G.; Ressier, L., "Nanoparticle-based strain gauges fabricated by convective self assembly: strain sensitivity and hysteresis with respect to nanoparticle sizes," The J. Phys. Chem. C 117 (4), 1935-1940 (2013).

[24] Cho, S. H.; Lee, S. W.; Yu, S.; Kim, H.; Chang, S.; Kang, D.; Hwang, I.; Kang, H. S.; Jeong, B.; Kim, E. H.; Cho, S. M.; Kim, K. L.; Lee, H.; Shim, W.; Park, C., "Micropatterned pyramidal ionic gels for sensing broadrange pressures with high sensitivity," ACS Appl. Mater. Interfaces 9 (11), 10128-10135 (2017).

[25]Zhang, S.; Wang, F.; Peng, H.; Yan, J.; Pan, G., "Flexible highly sensitive pressure sensor based on ionic liquid gel film," ACS Omega 3 (3), 3014-3021 (2018).

[26] Yang, X.; Wang, Y.; Qing, X., "A flexible capacitive pressure sensor based on ionic liquid," Sensors (Basel) 18 (7), 2395 (2018).

[27]Zhu, Z.; He, X.; He, Q.; Fang, X.; Hu, Q.; Chen, H., "Ionic polymer pressure sensor with gradient shape based on ion migration," J. Appl. Phys. 125 (2), 024901 (2019).

[28] Yang, X.; Wang, Y.; Sun, H.; Qing, X., "A flexible ionic liquid-polyurethane sponge capacitive pressure sensor," Sensor Actuat. A: Phys. 285, 67-72 (2019).

[29] Su, Q.; Huang, X.; Lan, K.; Xue, T.; Gao, W.; Zou, Q., "Highly sensitive ionic pressure sensor based on concave meniscus for electronic skin," J. Micromech. Microeng. 30 (1), 015009 (2020).

[30] Song, Y.; Chen, H.; Su, Z.; Chen, X.; Miao, L.; Zhang, J.; Cheng, X.; Zhang, H., "Highly compressible integrated supercapacitor-piezoresistance-sensor system with CNT-PDMS sponge for health monitoring," Small 13 (39), 1702091 (2017).

[31] Nag, A.; Feng, S.; Mukhopadhyay, S. C.; Kosel, J.; Inglis, D., "3D printed mould-based graphite/PDMS sensor for low-force applications," Sensor Actuat. A: Phys. 280, 525-534 (2018).

[32] Madsen, F. B.; Zakaria, S.; Yu, L.; Skov, A. L., "Mechanical and electrical ageing effects on the long-term stretching of silicone dielectric elastomers with soft fillers," Adv. Eng. Mater. 18 (7), 1154-1165 (2016).

[33] Skov, A. L.; Yu, L., "Optimization techniques for improving the performance of silicone-based dielectric elastomers," Adv. Eng. Mater. 20 (5), 1700762 (2018).

[34] Ogliani, E.; Yu, L.; Mazurek, P.; Skov, A. L., "Designing reliable silicone elastomers for high-temperature applications," Polym. Degrad. Stabil. 157, 175-180 (2018).

[35] Liu, X.; Yu, L.; Nie, Y.; Skov, A. L., "Silicone elastomers with high - permittivity ionic liquids loading," Adv. Eng. Mater. 21 (10), 1900481 (2019).

[36] Coraucci, G.; de Oliveira, R.; Garcia, V.; Fruett, F., "A study of the geometrical correction factor and the membrane thickness on the sensitivity of the transversal piezoresistive pressure sensor," J. Integ. Circuit. Sys. 5 (2), 140-147 (2010). 